\title{
Utilization of drinking-water treatment residue to immobilize copper and zinc in sewage-sludge-amended soils
}

\begin{abstract}
In situ immobilization of copper and zinc using alum-treated drinking-water treatment residue (WTR) was selected for the remediation of sewage-sludge-amended soils. The WTR has a $\mathrm{pH}$ of 7.07 and, although its acid-neutralizing capacity (ANC) is low, utilization at high rates $(>2.5 \%)$ can help to increase the $\mathrm{pH}$ of the soil system. The minerals present in WTR, such as kaolinite, gibbsite and Fe-oxides, provide surfaces for the adsorption of heavy metals. From the soil-solution study, results showed that application of WTR had reduced Zn concentrations in the soil solutions, as compared to the control treatment. Removal of $\mathrm{Zn}$ occurred via precipitation, adsorption and possibly organic-matter complexation or chelation. From the glasshouse study, results showed that by using WTR, Zn uptake by maize can be reduced. Although the decrease in $\mathrm{Cu}$ concentrations in the soil-solution study was not apparent, due to the very low concentrations of $\mathrm{Cu}$ present, the glasshouse study did indicate a reduction in $\mathrm{Cu}$ uptake by the maize plants; suitable rates of WTR application for maize growth should be less than or equal to $10 \%$. In fact, there is an additional benefit of WTR application, whereby the rate of $2.5 \%$ can increase the dry weight of the maize plants. Thus, WTR can be recom-mended as a potential soil amendment to immobilize $\mathrm{Zn}$ in contaminated soil.
\end{abstract}

Keyword: Acid soil; Alum-treated water treatment residue; Maize growth performance; Soilsolution study 